\title{
Numerical Simulation of Saturated and Unsaturated Consolidation Behaviour of Marl Residual Soil
}

\author{
Ana Raič, Mijo Nikolić, Nataša Štambuk Cvitanović, Mirela Galić \\ University of Split, Faculty of Civil Engineering, Architecture and Geodesy, Matice hrvatske 15, 21000 Split, CROATIA \\ e-mail: ana.raic@gradst.hr
}

\section{SUMMARY}

Consolidation tests were performed on reconstituted marl samples under saturated and unsaturated conditions in the geomechanical laboratory at the Faculty of Civil Engineering, Architecture and Geodesy (FCEAG). Reconstituted marl samples were used to simulate the behaviour of marl residual soil as a final product of weathering. The experimental results were implemented in the Plaxis 2D finite element software, and saturated and unsaturated consolidation tests were simulated using hydro-mechanical coupling analysis. Material parameters for the Mohr-Coulomb and Hardening Soil models were calculated from the obtained experimental results. The validity of above mentioned constitutive models for marl residual soil was evaluated using the consolidation tests results and considering the values of axial displacement and void ratio as deformation indicators for saturated and unsaturated conditions. The validity of the input parameters for unsaturated analysis (i.e. the obtained SWCC fitting parameters) and the applied boundary conditions were evaluated considering the achieved degree of saturation value for each calculation phase.

KEY WORDS: marl; residual soil; saturated and unsaturated consolidation testing; Plaxis 2D; hydro-mechanical coupling.

\section{INTRODUCTION}

Problems associated with soft rock behaviour have been widely recognized in geotechnical engineering practice. Soft rocks can be defined as transitional material between hard rock and soil. They are generally considered a critical geomaterial due to their low strength and susceptibility to weathering which leads to disaggregation and crumbling [1]. Marls, which are a part of the Split area flysch formations, can be defined as soft rock. The weathering process in this area is usually a result of precipitation effects, i.e. physical weathering due to wetting and drying cycles. The alternation between fully saturated and dry conditions in the wettingdrying cycles implies the development of suction (the negative pore pressures) in the material pores. The effect of suction and unsaturated hydraulic conductivity on the weathering of soft rocks has been recognized by various authors [2-5] and the emphasis in the latest research 
trends is on the determination of unsaturated soil properties. The result of the weathering process is a transformation from a soft rock into a fine-grained material [6]. Therefore, to use this material in engineering practice, it is necessary to determine the properties of marl as an intact rock (pre-weathering material and/or early stages of weathering), coarse-grained material (the intermediate stage of weathering), and fine-grained material (marl residual soil as the final product of the weathering process). It is also necessary to specify the adequate constitutive model for numerical modelling of material behaviour since finite element software programs are widely used by geotechnical engineers.

The scope of this paper is the implementation of experimental results obtained by laboratory tests on marl residual soil in Plaxis 2D finite element software. Saturated and unsaturated oedometer tests were simulated using consolidation and fully-coupled analysis in Plaxis 2D. Since the behaviour of unsaturated soil is non-linear, new constitutive models, such as Barcelona Basic Model (BBM) [7], were developed to describe unsaturated behaviour. Although BBM has been implemented in Plaxis finite element code and it has been proven successful in the simulation of unsaturated behaviour [8], it is still not widely used in engineering practice due to its complexity. Therefore, Mohr-Coulomb and Hardening Soil models were verified against saturated and unsaturated oedometer test results.

\section{EXPERIMENTAL TESTS}

Experimental tests were conducted on a marl sample with a calcium carbonate content of $55.02 \%$, collected at the location of Žnjan (Split, Croatia) and labelled as sample 01/19. Intact marl samples are crushed to a silt-sized material to simulate the residual soil behaviour. All tests on reconstituted samples are performed according to the suggested testing methods and standards [9-13].

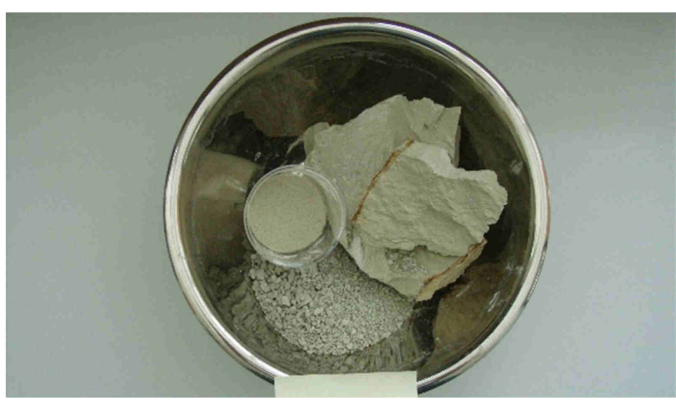

Fig. 1 Marl sample 01/19

\subsection{SATURATED CONSOLIDATION TESTS}

One-dimensional consolidation test on saturated reconstituted marl sample is performed in compliance with HRN EN ISO 17892-5:2017 standard [12] and using standard (incremental loading) oedometer test apparatus. The sample is prepared by hand compacting the silt-sized material in the oedometer ring at $18 \%$ water content ( $\approx$ plastic limit) to the desired density. Thereby, the dry density of $1.53 \mathrm{~g} / \mathrm{cm}^{3}$ is achieved. The preparation method is according to the HRN EN ISO 17892-5:2017 sample preparation method for recompacted specimens. The oedometer ring has a diameter of $69.50 \mathrm{~mm}$ and a height of $19.50 \mathrm{~mm}$.

After preparation, the sample is placed in the consolidation cell, the cell is filled with water, and initial vertical stress of $15 \mathrm{kPa}$ is applied. The test procedure consists of six loading 
increments (15 kPa, $25 \mathrm{kPa}, 50 \mathrm{kPa}, 100 \mathrm{kPa}, 200 \mathrm{kPa}$, and $400 \mathrm{kPa}$ ), followed by the unloading phase. Sample compressibility characteristics are determined based on the recorded axial displacement values. The test results for the loading phases are presented in Table 1 . Figure 2 shows the sample compressibility curve (void ratio $e$ vs vertical effective stress $\log \sigma_{v}$ ).

The value of the coefficient of permeability is determined based on the known value of coefficient of the consolidation, according to Eq. (1):

$$
k_{v}=\frac{c_{v} \cdot \gamma_{w}}{E_{\text {oed }}}
$$

Where: $k_{v}$ - coefficient of permeability (hydraulic conductivity) $(\mathrm{m} / \mathrm{s}), c_{v}$ - coefficient of consolidation $\left(\mathrm{m}^{2} / \mathrm{s}\right), \gamma_{w}$ - unit weight of water $\left(\mathrm{kN} / \mathrm{m}^{3}\right), E_{\text {oed }}$ - oedometer modulus $(\mathrm{kPa})$.

Table 1 Oedometer test results for loading phases

\begin{tabular}{cccccc}
\hline $\begin{array}{c}\text { No. } \\
\text { Increment }\end{array}$ & $\boldsymbol{\sigma}_{\boldsymbol{v}}$ & $\boldsymbol{e}$ & $\boldsymbol{E}_{\text {oed }}$ & $\boldsymbol{c}_{\boldsymbol{v}}$ & $\boldsymbol{k}_{\boldsymbol{v}}$ \\
$\mathrm{kPa}$ & - & $k P a$ & - & - & $\mathrm{m} / \mathrm{s}$ \\
\hline 0 & 0 & 0.751 & 1740 & $7.76 \times 10^{-8}$ & $4.38 \times 10^{-10}$ \\
1 & 15 & 0.736 & 1400 & $3.84 \times 10^{-8}$ & $2.69 \times 10^{-10}$ \\
2 & 25 & 0.724 & 1150 & $7.42 \times 10^{-8}$ & $6.35 \times 10^{-10}$ \\
3 & 50 & 0.686 & 1430 & $1.40 \times 10^{-8}$ & $9.60 \times 10^{-10}$ \\
4 & 100 & 0.627 & 2710 & $1.30 \times 10^{-8}$ & $4.70 \times 10^{-10}$ \\
5 & 200 & 0.567 & 4830 & $1.34 \times 10^{-8}$ & $2.72 \times 10^{-10}$ \\
6 & 400 & 0.502 & & &
\end{tabular}

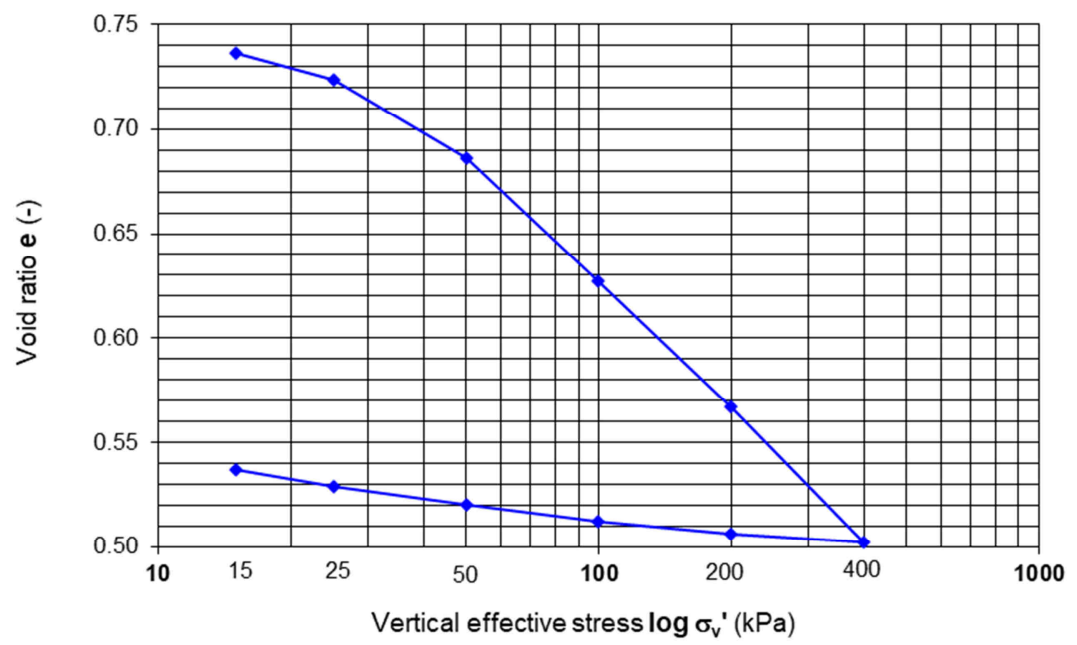

Fig. 2 Compressibility curve for the reconstituted marl sample 01/19 for saturated oedometer test

\subsection{UNSATURATED CONSOLIDATION TEST}

Unsaturated consolidation test is conducted using a CRS (Constant Rate of Strain) type system for unsaturated consolidation testing by GDS Instruments. The testing system consists of several main components: load frame, LVDT (Linear Variable Differential Transducer) as displacement transducer, CRS cell, HAEPD (High Air-Entry Porous Disc), pneumatic controller, and STDDPC (Standard Digital Pressure Controller). HAEPD used for this test has an air-entry value of $1500 \mathrm{kPa}$, which is the limit point for the imposed suction values in the system. The test is automated and controlled by the GDSLab software. The testing procedure is based on 
the axis translation technique [14]. In this technique, the environmental conditions in the unsaturated zone are simulated in the laboratory by subjecting the sample to certain values of pore air and pore water pressures. The achieved value of matric suction in the sample pores, after equilibration of the applied pressures, is equal to the differential between the pore air pressure $\left(u_{a}\right)$ and the pore water pressure $\left(u_{w}\right)$. The principles of the axis translation technique are explained in detail in the literature [14-17].

At FCEAG geotechnical laboratory, the axis translation technique was primarily used to obtain the Soil-Water Characteristic Curve (SWCC) of reconstituted marl samples. Therefore, the tests were performed by applying small constant stress $(15 \mathrm{kPa})$ in the first test stage and then six suction increments $(25 \mathrm{kPa}, 50 \mathrm{kPa}, 100 \mathrm{kPa}, 200 \mathrm{kPa}, 400 \mathrm{kPa}, 600 \mathrm{kPa})$. Additional consolidation tests considering the effect of vertical stress on SWCC by applying different load increments under different suction conditions are currently in progress. The axis translation technique in these tests is used to control the suction in the sample, which is achieved, e.g. for the first test stage with a suction increment of $25 \mathrm{kPa}$, by imposing $55 \mathrm{kPa}$ of air pressure in the cell using a pneumatic controller and $30 \mathrm{kPa}$ of water ('back') pressure through HAEPD using STDDPC. STDDPC is also used to monitor water drainage from the sample. When equilibrium conditions are reached, i.e. the back volume of water drained from the sample reaches a constant value, a new suction increment is set by increasing the value of air pressure in the cell while keeping the water pressure constant.

The reconstituted marl sample is prepared from the crushed silt-sized and clay-sized material by compacting the material in the oedometer ring $\left(d=50 \mathrm{~mm}, h_{0}=22 \mathrm{~mm}\right)$ at an initial water content of $16.04 \%$. The dry density of the prepared sample is $1.57 \mathrm{~g} / \mathrm{cm}^{3}$. The sample is then placed in the CRS cell, on top of the HEAPD, and saturated for 24 hours. The saturation phase is followed by a consolidation phase with a vertical load of $15 \mathrm{kPa}$ for the next 24 hours. In the following phases, suction increments are imposed and the duration of a single phase depends on the water drainage rate, which can range from 3 days to 15 days for higher suction values.

The performed tests resulted in axial displacement of the sample and back volume of water drained from the sample during the testing. Water content and degree of saturation for different suction values are calculated from the recorded back volume for the individual test stage, taking into account the sample volume change. Since radial deformation is not possible, the total volume change is calculated from the axial displacement values. Obtained water content values are used to define SWCC for $15 \mathrm{kPa}$ vertical stress level (Figure 3). SWCC, which represents the relationship between water content and suction, can be modelled using a variety of empirical equations. The water content can be expressed as gravimetric water content $w$, volumetric water content $\theta$ or degree of saturation $S$, whereas suction can be expressed as the pressure in $\mathrm{kPa}$ or as pressure head in $\mathrm{m}$. In this case, van Genuchten [18] equation (Eq. (2)) is selected as the SWCC model since Plaxis 2D input for the unsaturated groundwater flow is based on this equation.

The equation is expressed in terms of the degree of saturation versus pressure head to conform with Plaxis 2D input.

$$
\begin{gathered}
\Theta=\left[\frac{1}{1+(\alpha \cdot h)^{n}}\right]^{m} \\
\Theta=\frac{\theta-\theta_{r}}{\theta_{s}-\theta_{r}}
\end{gathered}
$$


Where: $\Theta$ - dimensionless water content according to the Eq. (3), $h$ - pressure head $(m)$ or suction $(k P a), \alpha, m, n$ - fitting parameters, $\theta$-water content at given suction value, $\theta_{r}-$ residual water content, $\theta_{s}$ - saturated water content.

The values of the fitting parameters for the van Genuchten model in Table 2, as well as for the van Genuchten - Mualem model (i.e. van Genuchten model in Plaxis 2D) in Table 3, are calculated using experimental results for sample 01/19 and regression analysis (the least squares method).

Table 2 Fitting parameters for van Genuchten model for reconstituted marl sample 01/19

\begin{tabular}{ccccc}
\hline $\boldsymbol{S}_{\boldsymbol{s}}$ & $\boldsymbol{S}_{\boldsymbol{r}}$ & $\boldsymbol{\alpha}$ & $\boldsymbol{m}$ & $\boldsymbol{n}$ \\
\hline 1.00 & 0.06509 & 0.00794 & 0.64805 & 1.41026 \\
\hline
\end{tabular}

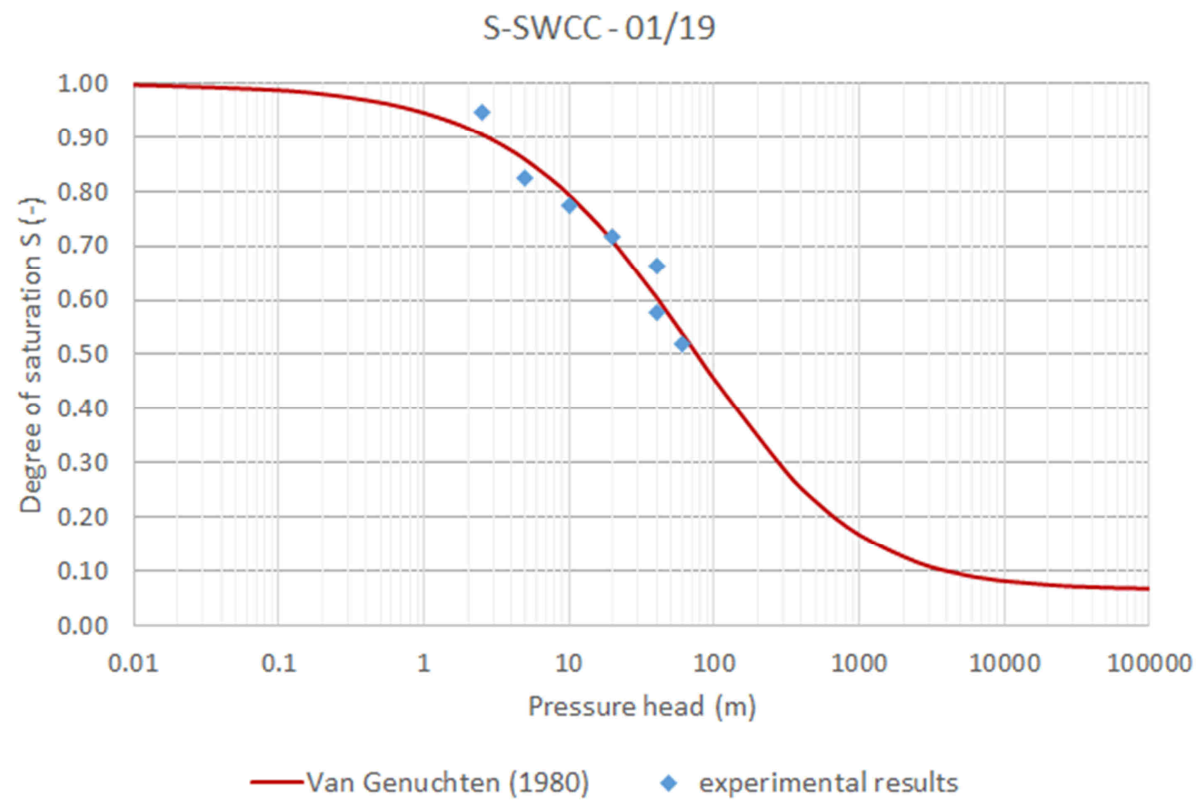

Fig. 3 Van Genuchten model of soil-water characteristic curve for reconstituted sample 01/19 (degree of saturation (-) vs pressure head (m))

\section{NUMERICAL SIMULATION}

Numerical simulation of saturated and unsaturated compressibility tests was performed in Plaxis 2D. Plaxis 2D is a two-dimensional finite element software developed for deformation, stability, and flow analysis in geotechnical engineering [19]. Proper analysis of the mechanical behaviour of saturated and partially saturated soils must take both deformation and groundwater flow into account [20]. This approach, in which displacement and pore pressure equations are solved simultaneously, is defined as coupled hydro-mechanical analysis. The coupled hydro-mechanical approach is based on the continuity equations for deformable media which are coupled with the mechanical equilibrium relations through the volumetric strain rate and the relationships between the stresses and pore pressures [21]. Both consolidation and fully-coupled analysis used in this research operate on the principles of hydro-mechanical coupling. 
The effective stress calculation in Plaxis 2D is based on Terzaghi's principle for saturated and dry soils, whereas Bishop's equation (Eq. (4)) is used in case of unsaturated conditions. Bishop [22] defined the effective stress as a function of net normal stress and matric suction by extending Terzaghi's equation. The use of Bishop's effective stress equation as a single stress state variable to describe the unsaturated soil behaviour instead of using the net normal stress and matric suction as two independent stress state variables is considered the main disadvantage of unsaturated calculations in Plaxis 2D.

$$
\sigma^{\prime}=\left(\sigma-u_{a}\right)+\chi\left(u_{a}-u_{w}\right)
$$

Where: $\left(\sigma-u_{a}\right)$ - net normal stress, $\left(u_{a}-u_{w}\right)$ - matric suction, $\sigma$ - total stress, $u_{a}$ - pore air pressure, $u_{w}$ - pore water pressure, $\chi$ - Bishop's parameter.

Bishop's parameter $\chi$ or the effective stress parameter is a factor related to the degree of saturation and it is used to decrease the effect of suction in the effective stress equation. The value of Bishop's parameter is 0 for dry soil state and 1 for fully saturated soil state. As for the unsaturated state, the value of Bishop's parameter should be determined experimentally. However, Plaxis 2D simplifies this problem by assuming the value of this parameter equal to the effective saturation (Eq. (7)) [20]. The Bishop's effective stress calculation procedure for unsaturated soil state in Plaxis 2D takes the form of Eqs. (5-9), where Eq. (9) is the final simplified form of the Bishop's effective stress [19]. It should be noted that in Plaxis 2D all compressive stresses and forces are taken to be negative, whereas all tensile stresses and forces are taken to be positive, pore pressures included [19].

$$
\begin{gathered}
\sigma^{\prime}=\sigma-\left(\chi \cdot p_{\text {water }}+(1-\chi) \cdot p_{a}\right) \\
p_{\text {water }}=p_{\text {steady }}+p_{\text {excess }} \\
\chi=S_{\text {eff }}=\frac{s-S_{r}}{S_{s}-S_{r}} \\
p_{\text {active }}=S_{\text {eff }} \cdot p_{\text {water }} \\
\sigma^{\prime}=\sigma-p_{\text {active }}
\end{gathered}
$$

Where: $p_{\text {water }}$ - pore water pressure, $p_{a}$ - atmospheric pressure (in Plaxis $2 \mathrm{D}$ it is taken as the zero reference level), $p_{\text {steady }}$ - steady-state pore pressure, $p_{\text {excess }}$ - excess pore pressure, $S_{\text {eff }}$ - effective degree of saturation, $S$ - degree of saturation, $S_{r}$ - residual degree of saturation, $S_{S}$ saturated degree of saturation, $p_{\text {active }}$ - active pore pressure.

In the unsaturated zone, the degree of saturation $S$ (Eq. (7)) is suction dependent, and the dependency is defined by inputting the soil-water characteristic curve (SWCC) in the Plaxis 2D material data set. The hydraulic models available in Plaxis 2D are van Genuchten, linearised van Genuchten, spline, and saturated. Van Genuchten model, used in this research, has the simplified van Genuchten - Mualem form, where the three-parameter van Genuchten equation (Eq. (10)) is converted to a two-parameter equation by assuming the value of the third fitting parameter according to Eq. (11):

$$
\begin{gathered}
S(\psi)=S_{r}+\left(S_{S}-S_{r}\right)\left[1-\left(g_{a}|\psi|\right)^{g_{n}}\right]^{g_{c}} \\
g_{c}=\frac{1-g_{n}}{g_{n}}
\end{gathered}
$$

Where: $\psi$ - suction defined as pressure head in $\mathrm{m}\left(\psi=-\frac{p_{w}}{\gamma_{w}}\right), g_{a}, g_{n}, g_{c}$ - fitting parameters.

Plaxis 2D input SWCC for reconstituted sample 01/19 is shown in Figure 4. Curve parameters are listed in Table 3. 
A. Raič, M. Nikolić, N. Štambuk Cvitanović, M. Galić: Numerical simulation of saturated and unsaturated consolidation behaviour of marl residual soil

Table 3 Input parameters for van Genuchten model in Plaxis 2D for reconstituted marl sample 01/19

\begin{tabular}{cccc}
\hline $\boldsymbol{S}_{\boldsymbol{s}}$ & $\boldsymbol{S}_{\boldsymbol{r}}$ & $\boldsymbol{g}_{\boldsymbol{a}}$ & $\boldsymbol{g}_{\boldsymbol{n}}$ \\
\hline 1.00 & 0.06509 & 0.14634 & 1.31997 \\
\hline
\end{tabular}

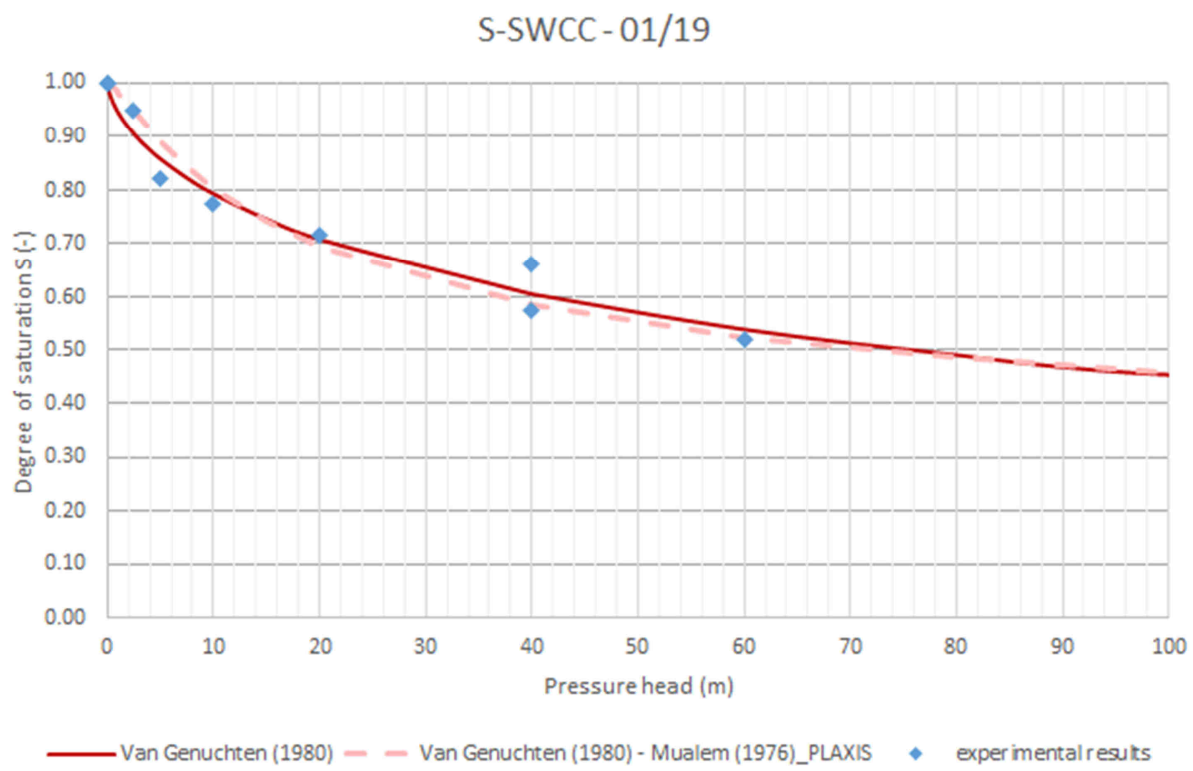

Fig. 4 SWCC for reconstituted sample 01/19 prepared for Plaxis 2D input

Relative permeability in the unsaturated zone is suction dependent as well. In Plaxis 2D, it is calculated using the effective saturation value, according to Eq. (12) [23] based on van Genuchten - Mualem expression for relative hydraulic conductivity [18, 24]:

$$
k_{\text {rel }}(S)=\max \left[\left(S_{e f f}\right)^{g_{l}}\left(1-\left(1-S_{e f f}\left(\frac{g_{n}}{g_{n}-1}\right)\right)^{\left(\frac{g_{n}-1}{g_{n}}\right)}\right)^{2}, 10^{-4}\right]
$$

Where: $g_{l}$ - fitting parameter.

Fitting parameter $g_{l}$ accounts for the correlation between pores and for the flow path tortuosity, and it contributes to the flexibility of Eq. (12) [24]. The value of the fitting parameter $g_{l}$ depends on the soil type and should be determined experimentally. Since the value of this parameter for marl residual soil has not been laboratory determined nor known in the literature, the value of 0.50 has been accepted. According to $[18,24]$, the value of 0.50 is determined as the value for which the square deviation, averaged over a great number of soils, takes a minimum value.

\subsection{MATERIAL MODELS}

Material models are used to define the mechanical behaviour of the soil. They are described by a set of mathematical equations that give the relationship between stress and strain [23]. Plaxis 2D offers a wide range of different material models. For this research, Mohr-Coulomb and Hardening Soil models were selected for numerical verification of the conducted consolidation tests. 
The Mohr-Coulomb (MC) model is a simple linear elastic perfectly plastic model where the linear elastic part is based on Hook's law of isotropic elasticity, whereas the perfectly plastic part is based on the Mohr-Coulomb failure criterion [23]. Plaxis 2D requires four basic input parameters for the MC model: $E$ - Young's modulus, $v$ - Poisson's ratio, $c$ - cohesion, $\varphi-$ friction angle, and $\psi$ - dilatancy angle.

The values of Young's modulus are calculated from the known Poisson's ratio and oedometer modulus values, according to Eq. (13). Thereby, the value of Young's modulus is obtained for different stress increments in the oedometer test. For numerical simulation of saturated consolidation test with a unique value of $E^{\prime}$ for all calculation phases, an average value of Young's modulus is taken as a reference.

$$
E^{\prime}=E_{o e d}^{\prime} \frac{(1+v)(1-2 v)}{(1-v)}
$$

The values of cohesion and friction angle are derived from direct shear test results, according to the HRN EN ISO 17892-11:2019 standard [13]. Since cohesive soils exhibit a small amount of dilatancy, the dilatancy angle value is taken to be $\psi \approx 0^{\circ}$. The values of input parameters for the MC model are listed in Table 4.

Table 4 Mohr-Coulomb model input parameters for reconstituted marl sample 01/19

\begin{tabular}{|c|c|c|c|c|c|c|c|c|c|c|}
\hline \multicolumn{6}{|c|}{$\boldsymbol{E}^{\prime *}\left(k N / m^{2}\right)$} & $\overline{\boldsymbol{E}}^{\prime * *}$ & $v^{\prime}$ & $c^{\prime} r e f$ & $\varphi^{\prime}$ & $\psi^{\prime}$ \\
\hline 15 & 25 & 50 & 100 & 200 & 400 & $\left(\mathrm{kN} / \mathrm{m}^{2}\right)$ & $(-)$ & $\left(\mathrm{kN} / \mathrm{m}^{2}\right)$ & $\left(^{\circ}\right)$ & $\left({ }^{\circ}\right)$ \\
\hline$k P a$ & $k P a$ & $k P a$ & $k P a$ & $k P a$ & $k P a$ & & & & & \\
\hline 1292.60 & 1040 & 854 & 1062 & 2013 & 3588 & 1641.58 & 0.30 & 11.30 & 27.70 & 0.00 \\
\hline
\end{tabular}

The Hardening Soil (HS) model is an advanced soil model based on the hyperbolic relationship between the vertical strain and the deviatoric stress in primary triaxial loading, developed by Schanz et al. [25]. HS model includes two types of hardening - shear hardening (used to model irreversible strains due to primary deviatoric loading) and compression hardening (used to model irreversible plastic strains due to primary compression in oedometer and isotropic loading) [23]. Apart from the parameters necessary for MC model input (such as $c^{\prime}, \varphi^{\prime}$ and $\psi^{\prime}$ ), the HS model in Plaxis 2D requires the input of additional basic and advanced parameters: $E_{50}{ }^{r e f}$ - secant stiffness in standard drained triaxial test, $E_{o e d}{ }^{r e f}$ - tangent stiffness for primary oedometer loading, $E_{\text {ur }}$ ref - unloading/reloading stiffness, $m$ - power for the stress-level dependency of stiffness, $v_{u r}$ - Poisson's ratio for unloading-reloading, $p^{\text {ref }}$ - reference stress for stiffness, $K_{0}{ }^{N C}-K_{0}$-value for normal consolidation, and $R_{f}$ - failure ratio.

The values of $E_{50}{ }^{\text {ref }}$ and $E_{u r}$ ref are derived from triaxial test results, where $E_{50}{ }^{r e f}$ is determined from a triaxial stress-strain curve for mobilization of $50 \%$ of the maximum shear strength $q_{f}$, and $E_{u r} r e f$ is determined as the reference Young's modulus for unloading-reloading path corresponding to the reference pressure $p^{\text {ref }}$ [25]. Since the HS model does not involve a fixed relationship between the drained triaxial stiffness $E_{50}$ and the oedometer stiffness $E_{\text {oed }}$, the value of $E_{\text {oed }}$ ref should be determined independently from the oedometer test results [25]. Therefore, $E_{\text {oed }}{ }^{r e f}$ represents the value of tangent stiffness at vertical stress equal to $p^{\text {ref. }}$.

Since the results of triaxial testing were not available at the time of this research, we were unable to calculate the exact values of $E_{50}$ ref and $E_{u r}$ ref for residual marl soil. Instead, the stiffness parameters of the HS model were calculated from the alternative parameters, i.e. compression index $C_{c}$, swelling index $C_{s}$ and initial void ratio $e_{i n i t}$, known from the oedometer test results. These relationships are given with Eqs. (14-16) [23]: 


$$
\begin{gathered}
C_{c}=\frac{2.3\left(1+e_{i n i t}\right) p^{r e f}}{E_{\text {oed }}^{r e f}} \\
C_{S} \approx \frac{2.3\left(1+e_{\text {init }}\right)\left(1+v_{u r}\right)\left(1-2 v_{u r}\right) p^{r e f}}{\left(1-v_{u r}\right) E_{u r}^{r e f} K_{0}} \\
E_{50}^{r e f}=1.25 E_{\text {oed }}^{r e f}
\end{gathered}
$$

When inputting the alternative parameters, the value of parameter $m$ is automatically set to 1 . The values of input parameters for the HS model are listed in Table 5.

Table 5 Hardening Soil input parameters for reconstituted marl sample 01/19

\begin{tabular}{ccccccc}
\hline $\boldsymbol{C}_{\boldsymbol{c}}$ & $\boldsymbol{C}_{\boldsymbol{s}}$ & $\boldsymbol{e}_{\text {init }}$ & $\boldsymbol{v}_{\boldsymbol{u r}}$ & $\boldsymbol{p}^{\text {ref }}$ & $\boldsymbol{K o}_{0^{N C}}$ & $\boldsymbol{R}_{\boldsymbol{f}}$ \\
$(-)$ & $(-)$ & $(-)$ & $(-)$ & $\left(\mathrm{kN} / \mathrm{m}^{2}\right)$ & $(-)$ & $(-)$ \\
\hline 0.1996 & 0.0206 & 0.7510 & 0.20 & 100.00 & 0.5352 & 0.90 \\
& & & $($ default value) & $($ default value) & $\left(K_{0}^{N C}=1-\sin \varphi\right)$ & (default value) \\
\hline
\end{tabular}

\subsection{SATURATED CONSOLIDATION TEST MODEL}

A simple axisymmetric model with dimensions $34.75 \times 19.50 \mathrm{~mm}$ (radius $\mathrm{x}$ height of the sample) is selected to model the saturated oedometer test sample. The model dimensions are set following the dimensions of the testing equipment, i.e. the dimensions of the consolidation ring for the saturated oedometer test. 15-noded triangular mesh elements with very fine element distribution are used for finite element mesh generation. The sample model with generated mesh is shown in Figure 5. Displacement boundary conditions are set as normally fixed for side boundaries, fully fixed for the bottom boundary, and free for the sample top boundary. As for groundwater flow boundaries, they are set as closed for side boundaries and open to seepage for top and bottom boundary. Given that the saturated consolidation test is simulated, water conditions are set as the global water level on top of the sample. The groundwater flow through the sample is conditioned by the coefficient of permeability value given in the material data set. The inputted value of the coefficient of permeability is taken as an average of calculated $k_{v}$ values shown in Table 1.

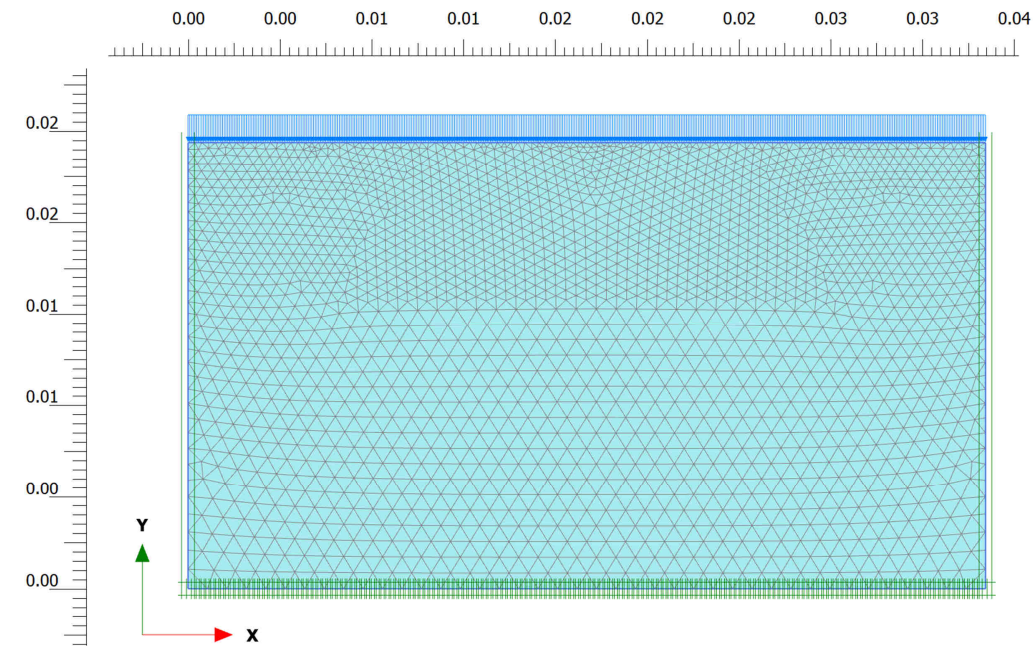

Fig. 5 Saturated consolidation test model

The loading is defined as a line load on the top boundary, and the value of the line load is changed through the calculation phases, according to the given test loading increment. The 
calculation procedure consists of initial phase with $K_{0}$ procedure, 12 loading phases (each loading increment modelled as a plastic phase for load input and a consolidation phase for time-dependent consolidation behaviour with time interval equal to the duration of experiment test phase), and 5 unloading phases (modelled as consolidation analysis with corresponding time intervals). The calculation procedure is shown in Table 6.

Table 6 Saturated consolidation test calculation procedure

\begin{tabular}{|c|c|c|c|}
\hline No. Phase & Phase name & Calculation type & $\begin{array}{c}\text { Calculation time } \\
\text { interval }\end{array}$ \\
\hline 1 & Initial phase & KO procedure & - \\
\hline 2 & Loading $15 \mathrm{kPa}$ & Plastic & - \\
\hline 3 & Loading 15 kPa_consolidation & Consolidation & $7200 \mathrm{~s}$ \\
\hline 4 & Loading $25 \mathrm{kPa}$ & Plastic & - \\
\hline 5 & Loading 25 kPa_consolidation & Consolidation & $86400 \mathrm{~s}$ \\
\hline 6 & Loading $50 \mathrm{kPa}$ & Plastic & - \\
\hline 7 & Loading 50 kPa_consolidation & Consolidation & $86400 s$ \\
\hline 8 & Loading $100 \mathrm{kPa}$ & Plastic & - \\
\hline 9 & Loading 100 kPa_consolidation & Consolidation & $86400 s$ \\
\hline 10 & Loading $200 \mathrm{kPa}$ & Plastic & - \\
\hline 11 & Loading 200 kPa_consolidation & Consolidation & $172800 s$ \\
\hline 12 & Loading $400 \mathrm{kPa}$ & Plastic & - \\
\hline 13 & Loading 400 kPa_consolidation & Consolidation & $86400 s$ \\
\hline 14 & Unloading $200 \mathrm{kPa}$ & Consolidation & $4200 \mathrm{~s}$ \\
\hline 15 & Unloading $100 \mathrm{kPa}$ & Consolidation & $5400 \mathrm{~s}$ \\
\hline 16 & Unloading $50 \mathrm{kPa}$ & Consolidation & $4800 \mathrm{~s}$ \\
\hline 17 & Unloading $25 \mathrm{kPa}$ & Consolidation & $5100 \mathrm{~s}$ \\
\hline 18 & Unloading $15 \mathrm{kPa}$ & Consolidation & $72000 \mathrm{~s}$ \\
\hline
\end{tabular}

\subsection{UNSATURATED CONSOLIDATION TEST MODEL}

The unsaturated oedometer test sample is modelled using an axisymmetric model with dimensions $25 \times 22 \mathrm{~mm}$ (radius $\mathrm{x}$ height of the sample). The model dimensions are set following the dimensions of the consolidation ring for the unsaturated oedometer test. The finite element mesh and displacement boundary conditions are set equivalent to the saturated oedometer test model (Figure 6). The groundwater flow boundary conditions are set as closed for side boundaries and open for seepage for a top boundary as well. However, since the permeability of $1500 \mathrm{kPa}$ HAEPD is lower than the permeability of the sample, in this model the bottom sample boundary is considered closed. The suction in the sample is achieved by imposing a desired value of suction as a pressure head on the sample model top boundary.

The loading is defined as line load on the top boundary with a constant value of $15 \mathrm{kPa}$ for all calculation phases. The calculation procedure for the unsaturated consolidation test consists of the initial phase with $K_{0}$ procedure, consolidation phase in saturated conditions with $15 \mathrm{kPa}$ load value, and 6 suction calculation phases modelled as fully-coupled analysis with corresponding time intervals. The calculation procedure is shown in Table 7. 


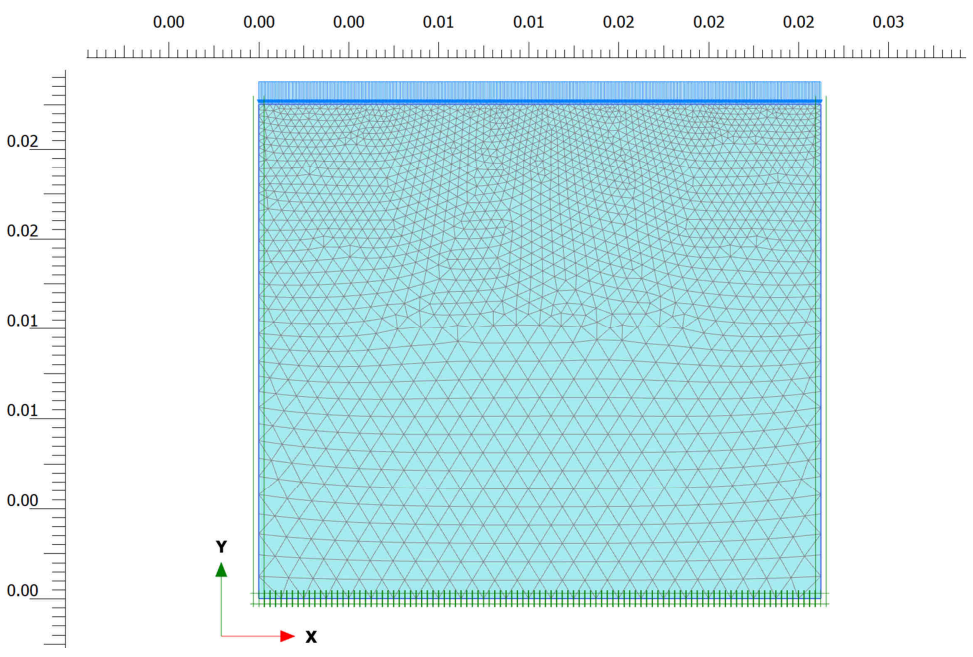

Fig. 6 Unsaturated consolidation test model

Table 7 Unsaturated consolidation test calculation procedure

\begin{tabular}{cccc}
\hline No. Phase & Phase name & Calculation type & Calculation time interval \\
\hline 1 & Initial phase & K0 procedure & - \\
2 & Consolidation $15 \mathrm{kPa}$ & Consolidation & $70580 \mathrm{~s}$ \\
3 & Suction $25 \mathrm{kPa}$ & Fully coupled flow-deformation & $345000 \mathrm{~s}$ \\
4 & Suction $50 \mathrm{kPa}$ & Fully coupled flow-deformation & $298300 \mathrm{~s}$ \\
5 & Suction $100 \mathrm{kPa}$ & Fully coupled flow-deformation & $219300 \mathrm{~s}$ \\
6 & Suction $200 \mathrm{kPa}$ & Fully coupled flow-deformation & $273700 \mathrm{~s}$ \\
7 & Suction $400 \mathrm{kPa}$ & Fully coupled flow-deformation & $1395000 \mathrm{~s}$ \\
8 & Suction $600 \mathrm{kPa}$ & Fully coupled flow-deformation & $256400 \mathrm{~s}$ \\
\hline
\end{tabular}

\section{RESULTS AND DISCUSSION}

The validity of the saturated consolidation test numerical models is verified by comparing the values of axial displacement in the numerical simulations with different soil models and the results of the oedometer test performed in the laboratory (Table 8). Numerically and experimentally obtained compressibility curves are compared as well (Figure 7).

Values of axial displacement obtained using the MC model in Plaxis 2D differ significantly from the experimental results, as shown in Table 8. The average error value is around $5.00 \%$, with a maximum value of $11.50 \%$ for unloading phases. The same can be observed in Figure $7 \mathrm{a}$, where the deformation is described graphically in terms of void ratio. When using a constant value of Young's modulus for all loading/unloading increments, the loading and unloading paths of the compressibility curve coincide, meaning that the MC model cannot correctly reproduce the relaxation of the material in the unloading stages. Compared with the experimentally obtained curve, the loading path of the curve for the model generally shows higher void ratio values for the same loading increment, whereby the increase in loading increases the deviation. If the corresponding value of Young's modulus is entered for each loading increment (calculated from the experimentally obtained $E_{\text {oed }}$ ), the error values decrease and the numerically obtained curve follows the experimental compressibility curve, as shown in Figure 7a (Plaxis MC (E=stress dependent) curve). However, it is neither practical nor advisable to change the value of Young's modulus for each loading phase. Therefore, the 
A. Raič, M. Nikolić, N. Štambuk Cvitanović, M. Galić: Numerical simulation of saturated and unsaturated consolidation behaviour of marl residual soil

inability of the MC model to reproduce stress-dependent stiffness is its main disadvantage. Consequently, it cannot be used to simulate the consolidation behaviour of marl residual soil.

On the other hand, the results of the HS model in Plaxis 2D are satisfactory. As shown in Figure $7 \mathrm{~b}$, the HS model curve and the experimental compressibility curve coincide very well, with minor deviation for lower stress increments (up to $50 \mathrm{kPa}$ ) and the unloading path. The average error for axial displacement is app. $0.60 \%$.

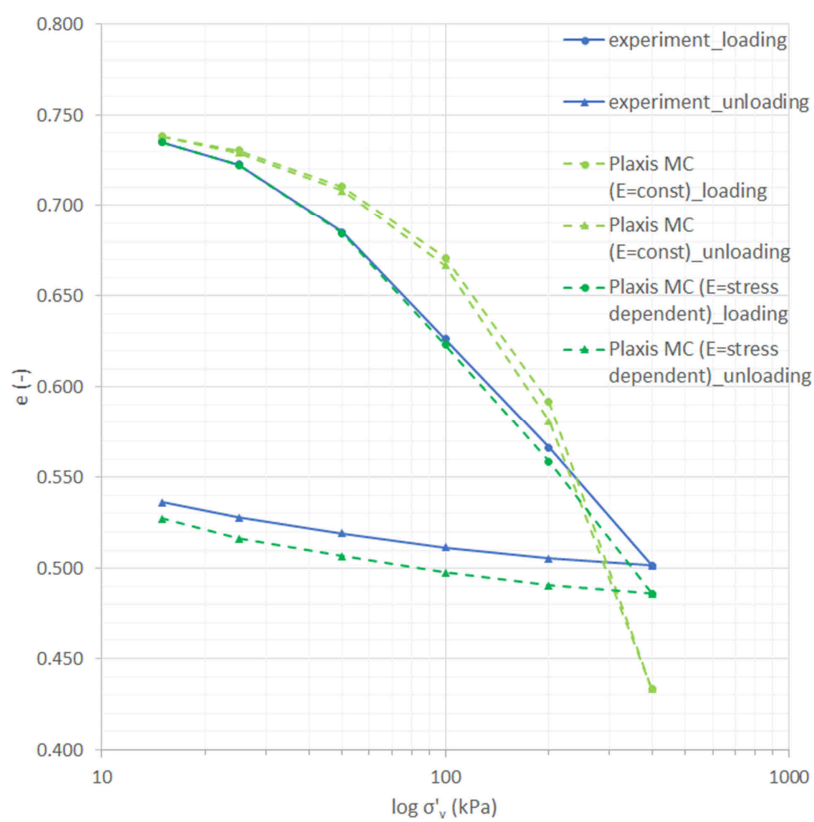

a)

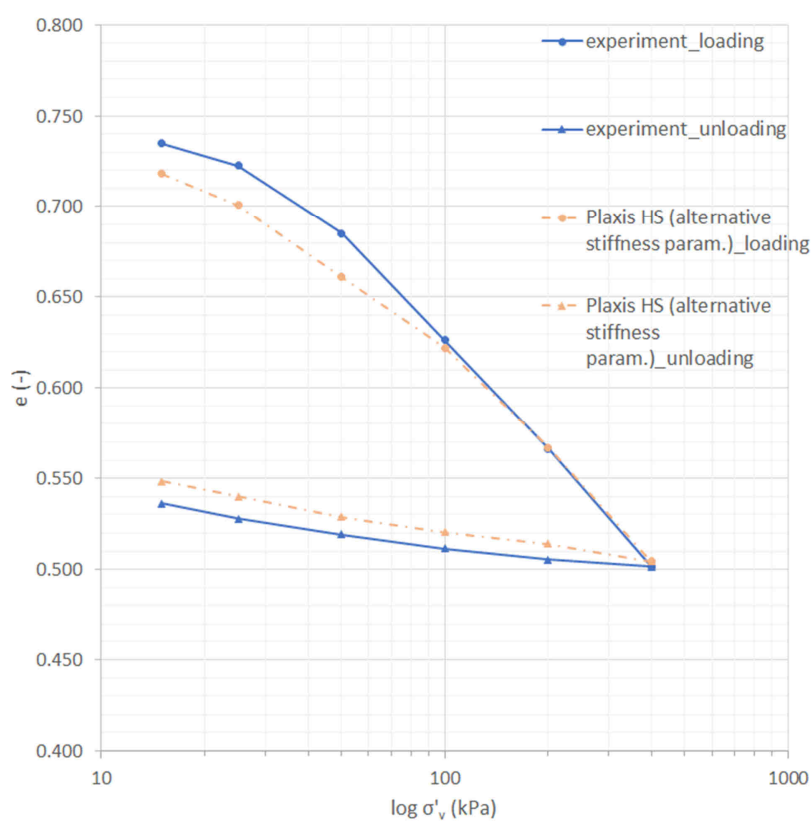

b)

Fig. 7 Compressibility curves $e-\log \sigma_{v}^{\prime}$ for saturated consolidation test: a) experiment vs Mohr-Coulomb model (Plaxis 2D), b) experiment vs Hardening Soil model (Plaxis 2D) 
A. Raič, M. Nikolić, N. Štambuk Cvitanović, M. Galić: Numerical simulation of saturated and unsaturated consolidation behaviour of marl residual soil

Table 8 Values of axial displacement for experiment and numerical simulations in Plaxis 2D for saturated consolidation test

\begin{tabular}{ccccccc}
\hline \multicolumn{2}{c}{ EXPERIMENT } & \multicolumn{2}{c}{$\begin{array}{c}\text { MOHR-COULOMB MODEL } \\
\text { (PLAXIS) }\end{array}$} & \multicolumn{2}{c}{$\begin{array}{c}\text { HARDENING SOIL MODEL } \\
\text { (PLAXIS) }\end{array}$} \\
\hline $\begin{array}{c}\boldsymbol{\sigma}_{\boldsymbol{v}} \\
(\mathrm{kPa})\end{array}$ & $\begin{array}{c}\boldsymbol{u}_{\boldsymbol{y}} \\
(\mathrm{mm})\end{array}$ & $\begin{array}{c}\boldsymbol{P} \boldsymbol{u}_{\boldsymbol{y}} \\
(\mathrm{mm})\end{array}$ & $\begin{array}{c}\boldsymbol{u}_{\boldsymbol{y}} \\
(\mathrm{mm})\end{array}$ & $\begin{array}{c}\boldsymbol{P} \boldsymbol{u}_{\boldsymbol{y}} \\
(\mathrm{mm})\end{array}$ & $\begin{array}{c}\boldsymbol{u}_{\boldsymbol{y}} \\
(\mathrm{mm})\end{array}$ & $\begin{array}{c}\boldsymbol{P u}_{\boldsymbol{y}} \\
(\mathrm{mm})\end{array}$ \\
\hline 15 & -0.168 & -0.168 & -0.132 & -0.132 & -0.356 & -0.356 \\
25 & -0.306 & -0.138 & -0.221 & -0.089 & -0.549 & -0.193 \\
50 & -0.724 & -0.418 & -0.441 & -0.220 & -0.923 & -0.374 \\
100 & -1.379 & -0.655 & -0.882 & -0.441 & -1.426 & -0.503 \\
200 & -2.048 & -0.669 & -1.765 & -0.883 & -2.040 & -0.614 \\
400 & -2.770 & -0.722 & -3.530 & -1.765 & -2.738 & -0.698 \\
200 & -2.727 & 0.043 & -1.883 & 1.647 & -2.630 & 0.108 \\
100 & -2.658 & 0.069 & -0.929 & 0.954 & -2.557 & 0.073 \\
50 & -2.572 & 0.086 & -0.467 & 0.462 & -2.465 & 0.092 \\
25 & -2.476 & 0.096 & -0.233 & 0.234 & -2.338 & 0.127 \\
15 & -2.381 & 0.095 & -0.133 & 0.100 & -2.247 & 0.091 \\
\hline
\end{tabular}

$\sigma_{\mathrm{v}}-$ vertical loading, $\mathrm{u}_{\mathrm{y}}-$ total displacement, $\mathrm{Pu} \mathrm{u}_{\mathrm{y}}-$ phase displacement

For unsaturated consolidation test numerical models, the main problem is to reach the set suction value in the calculation phase. When the experimental phase time interval is used, the value of suction in the numerical models is not uniformly distributed in the sample, which is especially noted in phases with higher suction values (Figure 8). Therefore, the value of the time interval for Plaxis 2D fully-coupled analysis should be determined by iterating the time interval until the target suction value is reached (Figure 9). Comparing the values of the axial displacement (Table 9) and the values of the degree of saturation for each suction increment (Table 10), the validity of the model is checked.

Table 9 Values of axial displacement for experiment and numerical simulations in Plaxis 2D for unsaturated consolidation test

\begin{tabular}{ccccccc}
\hline & \multicolumn{2}{c}{ EXPERIMENT } & \multicolumn{2}{c}{$\begin{array}{c}\text { MOHR-COULOMB } \\
\text { MODEL (PLAXIS) }\end{array}$} & \multicolumn{2}{c}{$\begin{array}{c}\text { HARDENING SOIL } \\
\text { MODEL (PLAXIS) }\end{array}$} \\
\hline $\begin{array}{c}\boldsymbol{s} \\
(\mathrm{kPa})\end{array}$ & $\begin{array}{c}\boldsymbol{u}_{\boldsymbol{y}} \\
(\mathrm{mm})\end{array}$ & $\begin{array}{c}\boldsymbol{P} \boldsymbol{u}_{\boldsymbol{y}} \\
(\mathrm{mm})\end{array}$ & $\begin{array}{c}\boldsymbol{u}_{\boldsymbol{y}} \\
(\mathrm{mm})\end{array}$ & $\begin{array}{c}\boldsymbol{P u}_{\boldsymbol{y}} \\
(\mathrm{mm})\end{array}$ & $\begin{array}{c}\boldsymbol{u}_{\boldsymbol{y}} \\
(\mathrm{mm})\end{array}$ & $\begin{array}{c}\boldsymbol{P} \boldsymbol{u}_{\boldsymbol{y}} \\
(\mathrm{mm})\end{array}$ \\
\hline $\begin{array}{c}\text { 0.01 (saturated } \\
\text { consolidation) }\end{array}$ & -0.491 & -0.491 & -0.188 & -0.188 & -0.429 & -0.429 \\
25 & & & & & & \\
50 & -0.586 & -0.095 & -0.489 & -0.301 & -0.907 & -0.478 \\
100 & -0.636 & -0.050 & -0.749 & -0.260 & -1.210 & -0.303 \\
200 & -0.684 & -0.048 & -1.187 & -0.438 & -1.599 & -0.389 \\
400 & -0.705 & -0.021 & -1.889 & -0.702 & -2.049 & -0.450 \\
600 & -0.728 & -0.023 & -3.000 & -1.111 & -2.543 & -0.494 \\
\hline
\end{tabular}

$s$ - suction, $u_{y}$ - total displacement, $P u_{y}$ - phase displacement 
A. Raič, M. Nikolić, N. Štambuk Cvitanović, M. Galić: Numerical simulation of saturated and unsaturated consolidation behaviour of marl residual soil

Table 10 Values of degree of saturation for experiment and numerical simulations in Plaxis 2D for unsaturated consolidation test

\begin{tabular}{c|ccccccc}
\hline $\boldsymbol{s}(\boldsymbol{k P a})$ & 0.01 & 25 & 50 & 100 & 200 & 400 & 600 \\
\hline $\boldsymbol{S}(\%)$ - experiment & 100.00 & 94.72 & 82.32 & 77.32 & 71.66 & 57.52 & 52.03 \\
$\boldsymbol{S}(\%)-$ numerical model & 100.00 & 94.85 & 89.20 & 80.34 & 69.46 & 58.45 & 52.55 \\
\hline
\end{tabular}

s-suction, $\mathrm{s}$ - degree of saturation

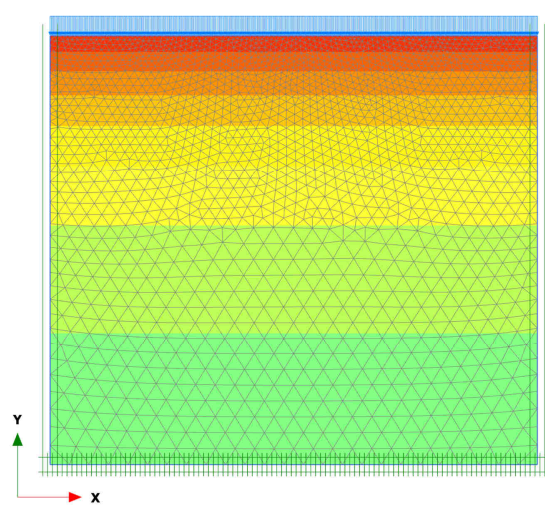

a)

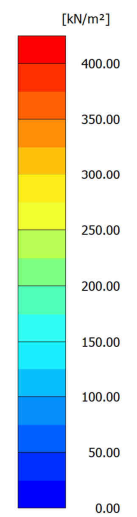

0.00

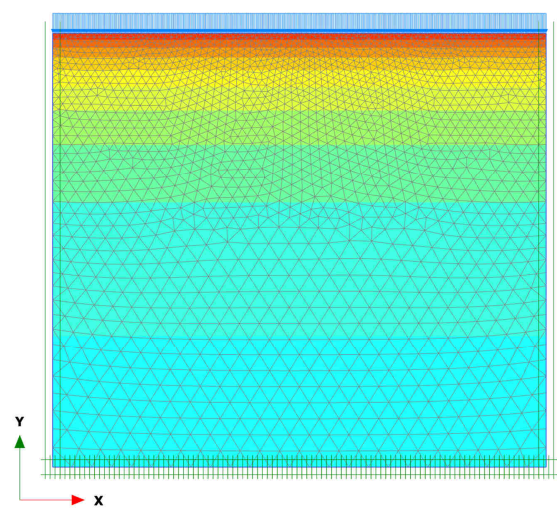

b)

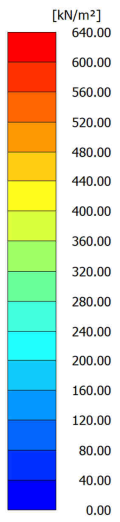

0.00

Fig. 8 Distribution of suction pressure for experimental time interval: a) $400 \mathrm{kPa}$ suction phase, b) $600 \mathrm{kPa}$ suction phase

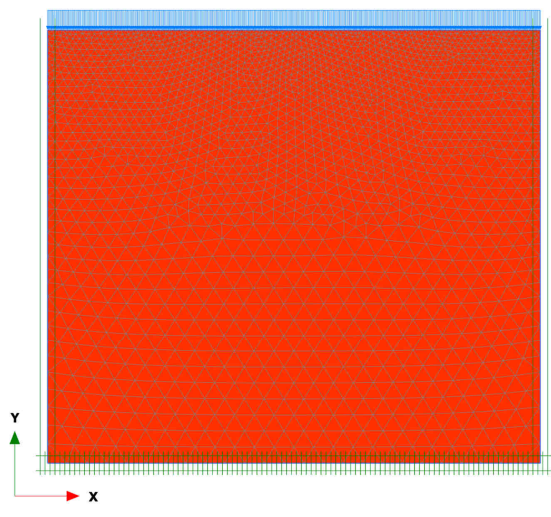

a)

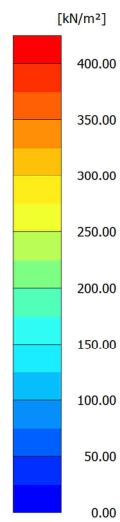

0.00

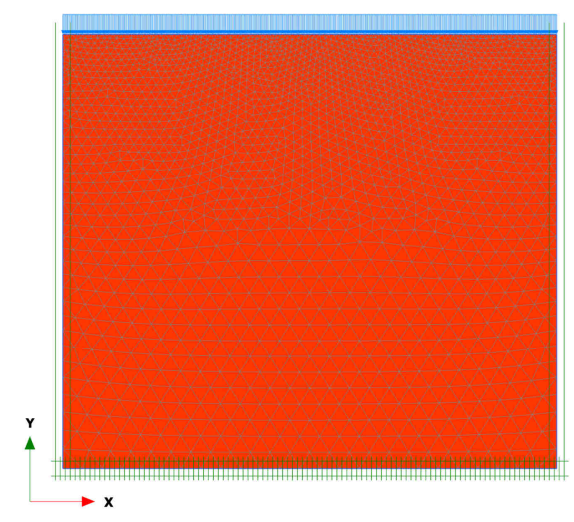

b)

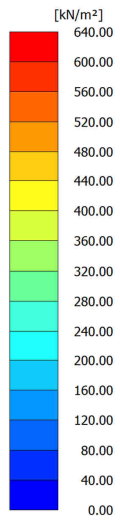

0.00

Fig. 9 Distribution of suction pressure for iterated time interval: a) $400 \mathrm{kPa}$ suction phase, b) $600 \mathrm{kPa}$ suction phase

As can be seen in Figure 8, for suction values greater than $25 \mathrm{kPa}$, the equilibrium of suction pressure throughout the sample is not achieved in the experimental time interval. Uniform distribution of suction pressure is achieved by increasing the calculation time interval. For each suction phase, the value of the degree of saturation is compared with the experimental values. Since the value of the degree of saturation does not depend on the material model used, but on the groundwater flow conditions and the inputted SWCC (which is the same for both observed models), the values obtained for MC and HS model numerical simulations are equal. 
These values do not significantly differ from the experimentally obtained results (Table 10), which confirms the validity of the set boundary conditions and the inputted SWCC parameters.

The validity of the MC and HS soil model is checked for unsaturated consolidation conditions as well. Since the unsaturated consolidation test is simulated for one loading level, the values of MC stiffness parameters are adopted for the loading increment of $15 \mathrm{kPa}$. The values of axial displacement as a deformability indicator for numerical simulations deviate significantly from the experimental test results, as shown in Table 9. The average error for both MC and HS models is app. $5.60 \%$ and has an increasing tendency with the increase of suction level.

Hence, the conclusion is that none of the material models tested has satisfactory accuracy regarding the simulation of unsaturated consolidation test results.

\section{CONCLUSIONS}

One-dimensional consolidation tests (i.e. oedometer tests) were conducted under saturated and unsaturated conditions on reconstituted marl samples. Intact marl samples were crushed to a silt-sized material to simulate the residual soil behaviour. Apart from saturated and unsaturated oedometer tests, additional laboratory tests (e.g. direct shear test) were performed to obtain necessary material parameters.

The experimental results were then implemented in Plaxis 2D finite element software to simulate the consolidation behaviour of residual marl soil in saturated and unsaturated conditions. The simulations were performed using Mohr-Coulomb (MC) and Hardening Soil (HS) constitutive models in combination with consolidation and fully-coupled analysis as forms of hydro-mechanical coupling. The results of numerical simulations were compared with the experimental results to verify the validity of inputted material parameters as well as model boundary conditions.

It has been proved that the application of the MC material model for the consolidation behaviour of residual marl soil is unable to accurately replicate the experimental results under both saturated and unsaturated conditions. The main disadvantage of this material model is its inability to reproduce the stress-dependent stiffness and material hardening in the unloading phase. On the other hand, the HS material model gives satisfactory results for the saturated consolidation test due to its implemented stress-dependent stiffness, but it does not meet the expectations in unsaturated consolidation simulations. Since the HS model input was based on alternative stiffness input parameters, i.e. compression index $C_{c}$, swelling index $C_{s}$, and initial void ratio $e_{\text {init }}$, known from the oedometer test results, triaxial tests should be performed in the future to obtain the values of $E_{50}{ }^{r e f}, E_{u r} r e f$, and $m$ for residual marl soil.

The hydraulic behaviour of the material in unsaturated conditions is defined by the inputted soil-water characteristic curve (SWCC) parameters, and it does not depend on the material model used. Therefore, the validity of the inputted SWCC parameters and the set boundary conditions for unsaturated consolidation test simulation was evaluated comparing the values of the degree of saturation achieved in numerical simulations for different suction levels and the experimental results. The simulations have shown that the values of the degree of saturation in numerical models coincide with the experimental results if the extended calculation time interval is applied. This result can be considered an example of successful implementation of experimental results in unsaturated numerical models and therefore used as a guideline in future simulations. 
The results of the conducted research show that the problem of unsaturated soil behaviour cannot be simplified and that the combination of "simpler" constitutive models and Bishop's effective stress equation implemented in Plaxis 2D is not sufficient to describe the complexity of unsaturated soil behaviour.

\section{ACKNOWLEDGEMENTS}

This work has been supported in part by the Croatian Science Foundation under the project "Experimental and numerical investigations of mechanisms in unsaturated geomaterials" (UIP2017-05-3429). It has also been partially supported through the project KK.01.1.1.02.0027, a project co-financed by the Croatian Government and the European Union through the European Regional Development Fund - the Competitiveness and Cohesion Operational Programme. The authors are deeply grateful for this support.

\section{REFERENCES}

[1] M.A. Kanji, Critical issues in soft rocks, Journal of Rock Mechanics and Geotechnical Engineering, Vol. 6, No. 3, pp. 186-195, 2014.

https://doi.org/10.1016/i.jrmge.2014.04.002

[2] R. Cardoso, E.E. Alonso, Degradation of Compacted Marls: A Microstructural Investigation, Soils and Foundations, Vol. 49, No. 3, pp. 315-327, 2009.

https://doi.org/10.3208/sandf.49.315

[3] E.E. Alonso, J.A. Pineda, R. Cardoso, Degradation of marls; two case studies from the Iberian Peninsula, Geological Society, London, Engineering Geology Special Publications, Vol. 23, pp. 47-75, 2010. https://doi.org/10.1144/EGSP23.5

[4] A. Wetzel, G. Einsele, On the physical weathering of various mudrocks, Bulletin of the International Association of Engineering Geology, Vol. 44, pp. 89-100, 1991.

https://doi.org/10.1007/BF02602713

[5] S.G. Fityus, M. Jeffery, K.J. Aglias, J.A. Johnston, J.V. Simmons, Weathering and Degradation of Shales and Mudrocks, In: Proceedings of $13^{\text {th }}$ ISRM International Congress of Rock Mechanics, Montreal, Canada, 2015.

[6] P. Miščević, T. Roje-Bonacci, Weathering process in Eocene flysch in region of Split (Croatia), Rudarsko-geološko-naftni zbornik, Vol. 13, No. 1, pp. 47-55, 2001.

[7] E.E. Alonso, A. Gens, A. Josa, A constitutive model for partially saturated soils, Geotechnique, Vol. 40, No. 3, pp. 405-430, 1990.

https://doi.org/10.1680/geot.1990.40.3.405

[8] A.A. Abed, P.A. Vermeer, Numerical simulation of unsaturated soil behaviour, International Journal of Computer Applications in Technology, Vol. 34, No. 1, pp. 2-12, 2009. https://doi.org/10.1504/IJCAT.2009.022697

[9] HRN U.B1.026: 1968 Determination of the carbonate content.

[10] HRN EN ISO 17892-2:2015 Geotechnical investigation and testing -- Laboratory testing of soil -- Part 2: Determination of bulk density (ISO 17892-2:2014, EN ISO 178922:2014) 
[11] HRN EN ISO 17892-12:2018 Geotechnical investigation and testing -- Laboratory testing of soil -- Part 12: Determination of liquid and plastic limits (ISO 17892-12:2018; EN ISO 17892-12:2018)

[12] HRN EN ISO 17892-5:2017 Geotechnical investigation and testing -- Laboratory testing of soil -- Part 5: Incremental loading oedometer test (ISO 17892-5:2017; EN ISO 17892$5: 2017)$

[13] HRN EN ISO 17892-10:2019 Geotechnical investigation and testing -- Laboratory testing of soil -- Part 10: Direct shear tests (ISO 17892-10:2018; EN ISO 17892-10:2018)

[14] L.A. Richards, A pressure-membrane extraction apparatus for soil solution, Soil Science, Vol. 51, No. 5, pp. 377-386, 1941. https://doi.org/10.1097/00010694-194105000-00005

[15] E. Romero, Controlled-suction techniques, Proceedings of $4^{\text {th }}$ National Brazilian Symposium on Unsaturated Soils, Porto Alegre, Brasil, pp. 535-542, 2001.

[16] F.A.M. Marihno, A.A. Take, A. Tarantino, Measurement of Matric Suction Using Tensiometric and Axis Translation Techniques, Geotechnical and Geological Engineering, Vol. 26, No. 6, pp. 615-631, 2008. https://doi.org/10.1007/s10706-008-9201-8

[17] S.K. Vanapalli, M.V. Nicotera, R.S. Sharma, Axis Translation and Negative Water Column Techniques for Suction Control, Geotechnical and Geological Engineering, Vol. 26, No. 6, pp. 645-660, 2008. https://doi.org/10.1007/s10706-008-9206-3

[18] M.T. van Genuchten, A Closed-form Equation for Predicting the Hydraulic Conductivity of Unsaturated Soils, Soil Science Society of America Journal, Vol. 44, No. 5, pp. 892-898, 1980. https://doi.org/10.2136/sssaj1980.03615995004400050002x

[19] R.B.J. Brinkgreve, S. Kumarswamy, W.M. Swolfs, F. Foria, PLAXIS 2D 2018 Reference Manual, Plaxis BV, Netherlands, 2018.

[20] V. Galavi, Groundwater flow, fully coupled flow deformation and undrained analyses in PLAXIS 2D and 3D, Internal Report, Plaxis BV, Netherlands, 2010.

[21] D. Sheng, D.W. Smith, S.W. Sloan, A. Gens, Finite element formulation and algorithms for unsaturated soils. Part I: Theory, International Journal for Numerical and Analytical Methods in Geomechanics, Vol. 27, No. 9, pp. 745-765, 2003.

https://doi.org/10.1002/nag.295

[22] A.W. Bishop, I. Alpan, G.E. Blight, I.B. Donald, Factors controlling the strength of partly saturated cohesive soils, In: Proceedings of the ASCE Research Conference on Shear Strength of Cohesive Soils, A.S.C.E., New York, USA, pp. 503-532, 1960.

[23] R.B.J. Brinkgreve, S. Kumarswamy, W.M. Swolfs, F. Foria, PLAXIS 2D 2018 Material Models Manual, Plaxis BV, Netherlands, 2018.

[24] Y. Mualem, A new model for predicting the hydraulic conductivity of unsaturated porous media, Water Resources Research, Vol. 12, No. 3, pp. 513-522, 1976.

https://doi.org/10.1029/WR012i003p00513

[25] T. Schanz, P.A. Vermeer, P.G. Bonnier, The Hardening Soil Model: Formulation and Verification, In: Beyond 2000 in Computational Geotechnics - 10 Years of PLAXIS, Balkema, Rotterdam, pp. 281-296, 1999. https://doi.org/10.1201/9781315138206-27 